\title{
Relações biométricas entre o estádio de maturação e a produtividade de híbridos de milho para produção de silagem
}

\section{Maity Zopollatto ${ }^{1}$, Luiz Gustavo Nussio ${ }^{1}$, Solidete de Fátima Paziani ${ }^{2}$, José Leonardo Ribeiro ${ }^{1}$, Jhones Onorino Sarturi ${ }^{1}$, Gerson Barreto Mourão ${ }^{3}$}

${ }^{1}$ Departamento de Zootecnia, USP/ESALQ.

${ }^{2}$ Apta Regional, SP.

${ }^{3}$ Departamento de Ciências Exatas, USP/ESALQ.

RESUMO - Avaliaram-se o teor de matéria seca (MS) da planta e do colmo e a produtividade de MS da planta, do colmo e dos grãos de híbridos de milho colhidos em diversos estádios de maturação. Utilizou-se um delineamento experimental de blocos casualizados, em esquema fatorial $8 \times 6 \times 2$, composto de oito épocas de corte, seis híbridos de milho e duas safras de avaliação (2001/2002 e 2002/2003). Os híbridos CO 32, AG 5011, P 3041, DKB 333B, AG 1051 e Z 8550 foram colhidos ao atingirem 50\% de florescimento masculino (emissão do pendão), 15 dias após esta data e, posteriormente, a cada semana, totalizando oito cortes. O híbrido CO 32 apresentou os maiores teores de MS da planta e do colmo e a menor produtividade de colmo, enquanto, no híbrido P 3041, foram obtidos os menores teores de MS da planta e do colmo. O avanço da maturação aumentou o teor de MS da planta (de 14,5 para 46\%) e do colmo (de 16,9 para 28\%) e aumentou a produtividade de MS da planta (de 9,6 para 20,9 t MS/ha) e dos grãos (de 0 para 9,3 t MS/ha). Na safra 2001/2002, a produtividade de colmo reduziu inicialmente e depois aumentou, enquanto, na safra 2002/2003, aumentou até o 6o corte e reduziu posteriormente. O teor de MS da planta teve baixa correlação com a produtividade de MS da planta $\left(r^{2}=0,27\right)$, do colmo $\left(r^{2}=0,13\right)$ e de grãos $\left(r^{2}=0,40\right)$. A produtividade de MS da planta apresentou correlação positiva alta com a produtividade de colmo $\left(r^{2}=0,83\right)$ e de grãos $\left(r^{2}=0,72\right)$. A avaliação individual do momento ideal de corte da planta para confecção de uma boa silagem é fundamental, uma vez que a janela de corte para ensilagem pode ser reduzida de acordo com as características específicas de cada material.

Palavras-chave: colmo, época de corte, forragem, grãos

\section{Biometric relations between maturity stage and productivity of corn cultivars for silage production}

\begin{abstract}
This experiment evaluated the plant and stem dry matter (DM) content, plant, stem and grain DM productivity of corn cultivars harvested in different maturity stages. A randomized block design, with a $8 \times 6 \times 2$ factorial scheme, composed of eight harvesting times, six corn cultivars and two evaluation harvests (2001/2002 and 2002/2003) was used. Cultivars CO 32, AG 5011, P 3041, DKB 333B, AG 1051 and Z 8550 were harvested when reaching 50\% of male flowering, 15 days after this date and later, every week, totalizing eight harvesting times. Cultivar CO 32 showed the highest plant and stem DM content, and the lowest stem DM production, while cultivar P 3041 achieved the lowest plant and stem DM content. The maturity advance resulted in increased plant DM content, (from 14.5 to 46\%), stem DM content (from 16.9 to 28\%), plant DM production (from 9.6 to $20.9 \mathrm{t} \mathrm{DM} / \mathrm{ha}$ ) and grain production (from 0 to $9.3 \mathrm{t} \mathrm{DM} / \mathrm{ha}$ ). In the 2001/2002 harvest, the production was initially reduced and then increased, while in the 2002/2003 harvest, the production increased up to the $6^{\text {th }}$ harvest and then reduced again. The plant DM content showed low correlations with plant DM production $\left(r^{2}=0.27\right)$, stem DM production $\left(r^{2}=0.13\right)$ and grain production $\left(r^{2}=0.40\right)$. The plant DM production showed high positive correlation with stem production $\left(r^{2}=0.83\right)$ and grain production $\left(r^{2}=0.72\right)$. The individual evaluation of the ideal plant harvesting time for a good silage production is fundamental, once the harvesting window for ensilage can be reduced in function of specific characteristics of each material.
\end{abstract}

Key Words: forage, grains, harvesting time, stem

\section{Introdução}

Híbridos de milho com boa produtividade de grãos e de matéria seca (MS) são recomendados para a produção de silagens. No entanto, o teor de matéria seca da silagem de milho depende do estádio de maturação da planta no momento da colheita (Bal et al., 1997). A produtividade da cultura de milho para silagem está relacionada a diversas características, 
algumas inerentes à planta, como ciclo, dureza de endosperma, altura da planta e proporção de grãos, e outras ao ambiente, como condições climáticas, tratos culturais, densidade de semeadura e época de corte.

O avanço do ciclo vegetativo da planta é representado principalmente pelo acúmulo de MS, que, na fase vegetativa, ocorre nos componentes da fração fibrosa da planta (colmos e folhas). Posteriormente, na fase reprodutiva, o acúmulo de MS passa a ocorrer nos grãos. Portanto, o avanço da maturação representa aumentos gradativos na produtividade de MS e concomitante redução nas produtividades de matéria fresca (MF). Beleze et al. (2003) verificaram produções de MS de 16.100 a $18.400 \mathrm{~kg} /$ ha quando o teor de MS da planta aumentou de 29,2 para 42,5\%.

Em estudo sobre o efeito da maturação da planta sobre a produtividade, qualidade e preservação da planta de milho para silagem, Darby \& Lauer (2002) constataram que a máxima produção da fração fibrosa foi atingida quando a planta iniciou sua fase reprodutiva e que, após esta fase, o material perdeu gradativamente qualidade sem apresentar ganhos de produção.

Silva et al. (1999) avaliaram mais de 20 híbridos de milho para silagem e observaram que plantas colhidas com grãos no estádio farináceo duro apresentaram produtividade de colmo e folhas de $4.745 \mathrm{~kg}$ MS/ha para o material menos produtivo (DINA 887) e atingiu produtividade máxima de 11.619 kg MS/ha para o híbrido COL FO 01, evidenciando a grande variabilidade entre híbridos.

Segundo Beleze et al. (2003), com o avanço do estádio de maturação da planta, houve aumento na produtividade de grãos, que passou de $6.590 \mathrm{~kg} / \mathrm{ha}$ aos 125 dias após a semeadura (DAS) para $10.190 \mathrm{~kg} / \mathrm{ha}$ aos 164 DAS, com concomitante diminuição na produtividade dos componentes estruturais, representados pela lâmina foliar (de 1.100 para $280 \mathrm{~kg}$ MS/ha) e colmo+bainha (de 3.620 para $2.380 \mathrm{~kg} \mathrm{MS} / \mathrm{ha}$ ).

Neste estudo, avaliou-se o efeito da maturação sobre os teores de matéria seca da planta e do colmo, a produtividade de matéria seca da planta, do colmo e de grãos de híbridos de milho para produção de silagem.

\section{Material e Métodos}

O experimento foi realizado no Setor de Ruminantes do Departamento de Zootecnia da Universidade de São Paulo (USP/ESALQ), em Piracicaba, São Paulo, durante dois anos consecutivos, safra 2001/2002 e 2002/2003.

Adotou-se o delineamento experimental em blocos ao acaso com parcelas subdivididas no tempo, em esquema fatorial $8 \times 6 \times 2$, composto de oito épocas de corte, seis híbridos de milho e duas safras de avaliação (2001/2002 e 2002/2003). Os cultivares de milho utilizados foram: CO 32: híbrido triplo, grão semiduro e ciclo precoce; AG 5011: híbrido triplo, grão dentado e ciclo precoce; P 3041: híbrido triplo, grão duro e ciclo precoce; DKB 333B: híbrido simples, grão semiduro e ciclo normal; AG 1051: híbrido duplo, grão dentado e ciclo normal; Z 8550: híbrido triplo, grão semidentado e ciclo precoce.

Na parcela experimental, o milho foi semeado em seis linhas espaçadas a $80 \mathrm{~cm}$ e com $10 \mathrm{~m}$ de comprimento, totalizando $48 \mathrm{~m}^{2}$ por parcela. As linhas laterais das parcelas foram consideradas bordaduras e as duas linhas centrais constituíram as linhas úteis, onde foram efetuadas as medições.

A semeadura da safra 2001/2002 foi realizada no dia $31 / 11 / 2001$ e a da safra 2002/2003, no dia 3/12/2002. As sementes foram tratadas com o inseticida Futur ${ }^{\circledR}$ (Thiodicarb + micronutrientes) para o controle de pragas do solo e correção de micronutrientes. Na semeadura, realizada manualmente, foram colocadas duas sementes por cova a cada $22 \mathrm{~cm}$. A adubação de semeadura, realizada com base nos resultados da análise do solo, foi feita com NPK 8-20-20 (350 kg/ha). As parcelas receberam duas adubações de cobertura, 30 e 45 dias após a semeadura, com aplicação de $300 \mathrm{~kg} /$ ha da fórmula NPK 20-0-20. A correção do estande foi feita 15 a 30 dias após a semeadura para atingir população de 57.500 plantas/ha.

As datas de corte foram determinadas quando todas as parcelas de um mesmo cultivar atingissem por volta de $50 \%$ de florescimento masculino (50\% das plantas com emissão do pendão), 15 dias após esta data e posteriormente, a cada semana, totalizando oito cortes. Entretanto, na safra 2002/ 2003, como houve excesso de precipitação, não se realizou o $2^{\circ}$ corte, o que resultou em sete cortes. Na safra 2001/2002, os híbridos CO 32, AG 5011, P 3041, DKB 333B, AG 1051 e Z 8550 atingiram $50 \%$ de florescimento aos 67, 67, 63, 70, 70 e 63 dias após a semeadura, respectivamente, enquanto, na safra 2002/2003, o tempo foi de 64, 59, 59, 64, 64 e 59 dias após a semeadura, respectivamente.

Após o corte (Tabela 1), realizado a $5 \mathrm{~cm}$ do solo, as plantas de cada parcela foram agrupadas, identificadas e conduzidas até o laboratório, onde foram pesadas para determinação de massa fresca.

Cinco plantas foram separadas ao acaso, para fracionamento das partes (sabugo, grão, brácteas, folhas e colmo+bainha+pendão) e previamente pesadas para determinação da massa total. Cada fração foi pesada separadamente e picada, manualmente ou em picador mecânico, para homogeneização do material. Posteriormente, retirou-se uma amostra da planta inteira, correspondente a uma alíquota 
Tabela 1 - Época de corte (dias após a semeadura) dos híbridos de milho avaliados

\begin{tabular}{|c|c|c|c|c|c|c|c|c|}
\hline \multirow[t]{2}{*}{ Híbrido } & \multicolumn{7}{|c|}{ Corte - 2001/2002 } & \multirow[b]{2}{*}{8} \\
\hline & 1 & 2 & 3 & 4 & 5 & 6 & 7 & \\
\hline CO 32 & 67 & 80 & 88 & 94 & 102 & 109 & 116 & 122 \\
\hline AG 5011 & 67 & 80 & 88 & 94 & 102 & 109 & 116 & 122 \\
\hline P 3041 & 63 & 77 & 84 & 90 & 98 & 105 & 112 & 118 \\
\hline DKB 333B & 70 & 83 & 90 & 98 & 105 & 112 & 118 & 126 \\
\hline AG 1051 & 70 & 83 & 90 & 98 & 105 & 112 & 118 & 126 \\
\hline \multirow[t]{2}{*}{ Z 8550} & 63 & 77 & 84 & 90 & 98 & 105 & 112 & 118 \\
\hline & \multicolumn{7}{|c|}{ Corte - 2002/2003 } & \\
\hline CO 32 & 64 & - & 84 & 92 & 99 & 105 & 112 & 119 \\
\hline AG 5011 & 59 & - & 80 & 87 & 94 & 101 & 109 & 115 \\
\hline P 3041 & 59 & - & 80 & 87 & 94 & 101 & 109 & 115 \\
\hline DKB 333B & 64 & - & 84 & 92 & 99 & 105 & 112 & 119 \\
\hline AG 1051 & 64 & - & 84 & 92 & 99 & 105 & 112 & 119 \\
\hline Z 8550 & 59 & - & 80 & 87 & 94 & 101 & 109 & 115 \\
\hline
\end{tabular}

do total triturado, e amostras denominadas “colmo", representadas pela haste, pela bainha e pelo pendão, além de amostras de grãos. As amostras foram acondicionadas em sacos de papel, pesadas e mantidas em estufas de ventilação forçada a $60^{\circ} \mathrm{C}$, por cerca de 72 horas, para determinação do teor de MS do material (Campos et al., 2002).

Por meio dos dados obtidos, realizaram-se os cálculos dos seguintes índices: produtividade de matéria seca da planta (kg MS/ha); produtividade de matéria seca do colmo (kg MS/ha); e produtividade de grãos, com base na matéria seca (kg MS/ha).

Os resultados foram analisados segundo o procedimento PROC MIXED do programa estatístico SAS ${ }^{\circledR}$, versão 9.1.3 (SAS, 2004), em delineamento fatorial $8 \times 6 \times 2$. Na análise descritiva, utilizou-se a variável corte para obtenção das médias. A comparação de médias das interações que apresentaram diferenças significativas foi feita pelo teste $t$ de Student a 5\% de probabilidade.

Os híbridos com perfil temporal semelhante, determinado pelo do teste t de Student, foram agrupados no momento da elaboração das curvas de regressão. O modelo matemático incluiu os efeitos de tratamento, corte e safra, além do erro experimental. Os resultados são apresentados como médias ajustadas pelo método dos quadrados mínimos.

\section{Resultados e Discussão}

O teor médio de matéria seca da planta (Tabela 2) nas duas safras aumentou $(\mathrm{P}<0,05)$ com o avanço da época de corte, passando de 15\% MS no primeiro corte para aproximadamente $46 \%$ de MS no oitavo corte. A porcentagem de MS da planta, de 32 a 35\%, recomendada para ensilagem foi atingida 98 a 112 dias após semeadura (DAS) na safra
2001/2002, e 94 a 105 DAS na safra 2002/2003, correspondentes ao quinto e sexto cortes, com exceção do híbrido CO 32, que atingiu teor adequado entre quarto e quinto cortes (92 a 102 DAS).

Os híbridos de milho apresentaram perfis semelhantes nas duas safras avaliadas, embora na safra 2002/2003, os materiais tenham apresentado melhor desempenho produtivo, possivelmente em virtude da maior $(\mathrm{P}<0,05)$ densidade populacional (65.923 vs 56.380 plantas/ha) observada neste ano (dados não apresentados).

O ponto de colheita recomendado como ideal para ensilagem da planta de milho, correspondente a plantas com 32 a 35\% de MS (Bal et al., 1997; Nussio \& Manzano, 1999; Rosa et al., 2004), foi antecipado na safra 2002/2003, provavelmente em razão das temperaturas médias mais elevadas nos meses iniciais, além da ocorrência de um veranico no mês de fevereiro, quando se registrou precipitação média de 52,5 mm (no mesmo período da safra anterior, a precipitação média foi de 167,8 mm), que resultaram em maior taxa de acúmulo de graus-dia na segunda safra (dados não apresentados). Segundo Fancelli \& Dourado Neto (2000), o aumento da temperatura, principalmente noturna, além de intensificar o processo respiratório, contribui para a aceleração do acúmulo de graus-dia, encurtando o ciclo da cultura e reduzindo o aparato fotossintético e a quantidade de radiação interceptada, assim como o potencial de produção.

Os resultados observados neste estudo foram próximos aos descritos por Filya (2004), que observou idades de corte de 93 a 107 DAS para a planta atingir 28,2 a 35,8\% de MS. Em estudos conduzidos por Russell et al. (1992), períodos maiores de crescimento (133 DAS) foram necessários para a planta atingir a faixa de MS recomendada, assim como Wilkinson \& Hill (2003) também verificaram períodos de 
Tabela 2 - Teor médio de matéria seca da planta e do colmo (\%) dos híbridos de milho nas safras 2001/2002 e 2002/2003

\begin{tabular}{|c|c|c|c|c|c|c|c|c|}
\hline \multirow[t]{2}{*}{ Híbrido } & \multicolumn{7}{|c|}{ Corte } & \multirow[b]{2}{*}{8} \\
\hline & 1 & 2 & 3 & 4 & 5 & 6 & 7 & \\
\hline \multicolumn{9}{|c|}{ Teor de matéria seca da planta } \\
\hline CO 32 & $16,6 \mathrm{Af}$ & - & $24,4 \mathrm{Ae}$ & $29,6 \mathrm{Ad}$ & $37,8 \mathrm{Ac}$ & $42,7 \mathrm{Ab}$ & $50,4 \mathrm{Aa}$ & $55,8 \mathrm{Aa}$ \\
\hline AG 5011 & $13,0 \mathrm{Df}$ & - & $20,2 \mathrm{Ce}$ & $22,5 \mathrm{Cd}$ & $28,6 \mathrm{Cc}$ & $37,2 \mathrm{Bb}$ & $41,9 \mathrm{Ba}$ & $44,3 \mathrm{Ba}$ \\
\hline P 3041 & $13,6 \mathrm{Df}$ & - & $19,5 \mathrm{Ce}$ & $23,9 \mathrm{Cd}$ & $29,8 \mathrm{Cc}$ & $33,3 \mathrm{Cb}$ & $41,2 \mathrm{Ba}$ & 37,9Сa \\
\hline DKB 333B & $15,5 \mathrm{Be}$ & - & $23,2 \mathrm{ABd}$ & $28,7 \mathrm{ABC}$ & $30,1 \mathrm{Cc}$ & $35,7 \mathrm{BCb}$ & $38,1 \mathrm{Bab}$ & $43,2 \mathrm{BCa}$ \\
\hline AG 1051 & $15,8 \mathrm{Bf}$ & - & $22,1 \mathrm{Be}$ & $27,3 \mathrm{Bd}$ & 31,7ВCс & $35,7 \mathrm{BCb}$ & $39,0 \mathrm{Bb}$ & $48,2 \mathrm{Ba}$ \\
\hline Z 8550 & $14,7 \mathrm{Cf}$ & - & $20,4 \mathrm{Ce}$ & $24,1 \mathrm{Cd}$ & $33,1 \mathrm{Bc}$ & $36,8 \mathrm{Bb}$ & $43,0 \mathrm{Ba}$ & $46,1 \mathrm{Ba}$ \\
\hline $\mathrm{EPM}^{1}$ & 0,22 & - & 0,46 & 0,78 & 0,94 & 1,63 & 1,92 & 1,80 \\
\hline \multicolumn{9}{|l|}{ Safra } \\
\hline $2001 / 2002$ & $15,0 \mathrm{~h}$ & $17,8 \mathrm{~g}$ & $20,9 \mathrm{Bf}$ & $26,2 \mathrm{e}$ & $31,7 d$ & $36,0 \mathrm{Bc}$ & 39,9Bb & $45,3 a$ \\
\hline $2002 / 2003$ & $14,7 \mathrm{f}$ & - & $22,4 \mathrm{Ae}$ & $25,9 d$ & $32,0 \mathrm{c}$ & $37,8 \mathrm{Ab}$ & $44,6 \mathrm{Aa}$ & $46,6 a$ \\
\hline $\mathrm{EPM}^{1}$ & 0,13 & 0,21 & 0,26 & 0,43 & 0,55 & 0,88 & 1,10 & 1,04 \\
\hline \multicolumn{9}{|c|}{ Teor de matéria seca do colmo } \\
\hline CO 32 & $19,2 \mathrm{Ae}$ & - & $21,0 \mathrm{Ad}$ & $22,8 \mathrm{ABc}$ & 23,9Ac & $29,4 \mathrm{Ab}$ & $30,3 \mathrm{Ab}$ & 33,7Aa \\
\hline AG 5011 & $15,2 \mathrm{De}$ & - & $14,5 \mathrm{Ce}$ & $16,6 \mathrm{Ed}$ & 19,2 Cс & $20,5 \mathrm{Cbc}$ & $21,2 \mathrm{Db}$ & $23,5 \mathrm{Ca}$ \\
\hline P 3041 & $15,4 \mathrm{De}$ & - & $14,8 \mathrm{Cd}$ & $19,4 \mathrm{Dc}$ & $20,6 \mathrm{BCbc}$ & $21,0 \mathrm{Cb}$ & $23,9 \mathrm{Cc}$ & $24,2 \mathrm{Ca}$ \\
\hline DKB 333B & $17,2 \mathrm{BCd}$ & - & $20,3 \mathrm{Ac}$ & $23,4 \mathrm{Ab}$ & $21,2 \mathrm{Bc}$ & $23,9 \mathrm{Bb}$ & $24,2 \mathrm{Cb}$ & $26,4 \mathrm{BCa}$ \\
\hline AG 1051 & $16,7 \mathrm{Ce}$ & - & $19,8 \mathrm{Ad}$ & 21,7BCс & $21,6 \mathrm{Bc}$ & $25,1 \mathrm{Bb}$ & $23,6 \mathrm{Cb}$ & $27,5 \mathrm{Ba}$ \\
\hline Z 8550 & $17,9 B \mathrm{Be}$ & - & $17,8 \mathrm{Be}$ & $21,1 \mathrm{Cd}$ & $23,1 \mathrm{Ac}$ & $24,9 \mathrm{Bb}$ & $28,4 \mathrm{Ba}$ & 26,5BCab \\
\hline $\mathrm{EP}^{1}$ & 0,33 & - & 0,59 & 0,50 & 0,57 & 0,71 & 0,80 & 0,77 \\
\hline \multicolumn{9}{|l|}{ Safra } \\
\hline $2001 / 2002$ & $16,9 \mathrm{f}$ & $18,8 \mathrm{e}$ & 19,3Ае & $21,3 \mathrm{Ad}$ & $23,0 \mathrm{Ac}$ & $25,1 \mathrm{Ab}$ & $25,6 b$ & $28,0 \mathrm{Aa}$ \\
\hline $2002 / 2003$ & $16,9 d$ & - & $16,8 \mathrm{Bd}$ & $20,4 \mathrm{Bc}$ & $20,1 \mathrm{Bc}$ & $23,2 \mathrm{Bb}$ & 24,9 a & $25,9 \mathrm{Ba}$ \\
\hline $\mathrm{EP}^{1}$ & 0,19 & 0,37 & 0,34 & 0,29 & 0,33 & 0,41 & 0,46 & 0,44 \\
\hline
\end{tabular}

${ }^{1}$ EPM: erro-padrão da média.

Médias seguidas de letras diferentes, maiúsculas na coluna ou minúsculas na linha, diferem entre si $(\mathrm{P}<0,05)$ pelo teste t de Student.

130 a 144 DAS para a planta atingir 28,5 a 37,4\% de MS. Idades de corte bem superiores às observadas neste estudo (94 a 105 DAS) foram reportadas por Beleze et al. (2003) para o híbrido P 3041. Esses autores verificaram que o ponto de ensilagem foi obtido entre 141 e 149 DAS, diferença provavelmente ocasionada pelas condições climáticas, que diferem entre as regiões de avaliação, e pelas possíveis diferenças no tipo de solo e na adubação realizada em cada uma.

Maior teor de MS no momento da ensilagem foi observado por Cruz \& Pereira Filho (2001) em híbridos de ciclo precoce em comparação a materiais de ciclo normal. Neste estudo, não foi observada diferença entre os cultivares avaliados. Quando avaliados os teores de MS da planta, os híbridos P 3041 e DKB 333B apresentaram perfil semelhante ao longo do período de avaliação e, assim, foram agrupados para gerar as equações de regressão (Tabela 3). Os demais híbridos também apresentaram perfil semelhante e foram agrupados em outro grupo, gerando-se duas equações para o teor de MS da planta.

O efeito quadrático dos dias após semeadura (DAS) sobre a porcentagem de MS da planta nos híbridos de milho pode ser explicado pelas alterações ocasionadas pela maturação na participação dos componentes e na translocação de nutrientes entre estas frações da planta. Além disso, as condições externas (temperatura e precipitação) também afetam o acúmulo de MS da planta e, segundo Beleze et al. (2003), o tempo tem efeito cúbico sobre o teor de MS da planta.

Os teores médio de MS (\%) do colmo (Tabela 2) nas safras 2001/2002 e 2002/2003 aumentaram (P<0,05) com o avanço da maturação e, na maioria dos cortes, foram maiores ( $P<0,05)$ na safra 2001/2002. A porcentagem de MS do colmo quando a planta atingiu 32 a 35\% de MS foi de 23 a $25 \%$ na primeira safra e 20 a 23\% na safra 2002/2003, semelhante aos resultados obtidos por Neumann et al. (2006), que encontraram 22 a 26\% de MS no colmo no ponto de ensilagem. Os híbridos AG 5011 e P 3041 apresentaram os menores $(\mathrm{P}<0,05)$ teores de MS no colmo, enquanto o híbrido CO 32 apresentou os maiores valores $(\mathrm{P}<0,05)$. No ponto de ensilagem (planta entre 32 e 35\% MS), o teor de MS (\%) do colmo foi de 22,8 a 23,9\% para o híbrido CO 32 e de 19,2 a $25,1 \%$ para as demais cultivares.

Russell (1986) avaliou o efeito da maturação sobre as características da fração fibrosa da planta de milho e 
Tabela 3 - Equações de regressão do teor de matéria seca da planta e do colmo

\begin{tabular}{|c|c|c|}
\hline Híbrido & Safra $^{1}$ & Equação de regressão ${ }^{2}$ \\
\hline \multicolumn{3}{|c|}{ Teor de matéria seca da planta } \\
\hline CO 32, AG 5011, & $2001 / 2002$ & $\%$ MSP $=31,663-0,7407 *$ DAS $+0,0074 * \mathrm{DAS}^{2}$ \\
\hline AG 1051 e Z 8550 & $2002 / 2003$ & $\%$ MSP $=32,3129-0,7407 *$ DAS $+0,0074 * \mathrm{DAS}^{2}$ \\
\hline P 3041 e DKB 333B & $2001 / 2002$ & $\%$ MSP $=12,9011-0,2433 *$ DAS $+0,00416 *$ DAS $^{2}$ \\
\hline & $2002 / 2003$ & $\% \mathrm{MSP}=13,551-0,2433 * \mathrm{DAS}+0,00416 * \mathrm{DAS}^{2}$ \\
\hline
\end{tabular}

Teor de matéria seca do colmo

$\begin{array}{lll}\text { CO 32 } & 2001 / 2002 & \% \text { MSC }=39,3276-0,6247 * \text { DAS }+0,004776 * \text { DAS } \\ & 2002 / 2003 & \% \text { MSC }=39,3117-0,6247 * \text { DAS }+0,004776 * \text { DAS } \\ \text { AG 5011, P 3041, } & 2001 / 2002 & \% \text { MSC }=17,9878-0,1372 * \text { DAS }+0,001689 * \text { DAS } \\ \text { DKB 333B,AG 1051 e Z 8550 } & \text { \% MSC }=17,9719-0,1372 * \text { DAS + } 0,001689 * \text { DAS }{ }^{2}\end{array}$

1 Safra 2001/2002: CO 32 - 67 a 122 DAS; AG 5011 - 67 a 122 DAS; P 3041 - 63 a 118 DAS; DKB 333 B - 70 a 126 DAS; AG 1051 - 70 a 126 DAS; Z 8550 - 63 a 118 DAS; Safra 2002/2003: CO 32 - 64 a 119 DAS; AG 5011 - 59 a 115 DAS; P 3041 - 59 a 115 DAS; DKB $333 B$ - 64 a 119 DAS; AG 1051 - 64 a 119 DAS; Z 8550 59 a 115 DAS.

${ }^{2}$ MSP = teor de MS da planta; MSC = teor de MS do colmo; DAS = dias após a semeadura.

verificou valores de 21,8 a 25,2\% de MS no colmo. Apesar de terem sido obtidos no ponto de maturidade fisiológica da planta, esses valores foram bem próximos aos encontrados nos estádios mais avançados de crescimento da planta. Roth et al. (2004) também encontraram valores de 21 a 24,5\% de MS na fração colmo de híbridos de milho colhidos quando a planta apresentava 30,3 a 33,2\% de MS, grãos com 2/3 da linha de leite.

O híbrido CO 32 apresentou teor de MS do colmo diferente do obtido nos demais híbridos, portanto, criou-se para esse material uma curva de regressão individual (Tabela 3). No entanto, o tempo teve efeito quadrático $(\mathrm{P}<0,01)$ sobre essa variável em todos os híbridos.

Possivelmente, a mudança do dreno da planta após o florescimento, passando da fração fibrosa para a espiga (Ferreira, 2001), altera a translocação de nutrientes, de modo que, a partir deste momento, o colmo e as demais frações fibrosas passam a elevar o teor de MS, que atinge valores de 36,4\% MS (híbrido CO 32) e 27,5\% (demais materiais aos 126 DAS).

$\mathrm{O}$ avanço da maturação ocasionou aumento $(\mathrm{P}<0,05)$ da produtividade de MS da planta (MS), com as maiores produções $(\mathrm{P}<0,05)$ observadas na safra 2002/2003 na maioria dos cortes (Tabela 4). No ponto de ensilagem (planta com 32 a 35\% MS), as produções variaram em média de 15.165 a $20.762 \mathrm{~kg}$ MS/ha. Com o avanço da idade da planta, a produtividade de MS aumenta, em decorrência do maior teor de MS, ocasionado pela produção de grãos (Ballard et al., 2001; Filya, 2004). Nos pontos de ensilagem (5ㅇ e 6 o cortes), a produtividade de MS atingiu valores de $17.500 \mathrm{~kg} / \mathrm{ha}$ na safra 2001/2002, e $21.000 \mathrm{~kg} / \mathrm{ha}$ na safra 2002/2003. Produções semelhantes foram observadas por Cusicanqui \& Lauer (1999), de 14.700 a 19.300 kg MS/ha, Duarte et al. (2003), 13.100 a 22.800 kg MS/ha, Fernandes et al. (2004), 10.200 a $19.500 \mathrm{~kg}$ MS/ha, e Jaremtchuk et al. (2005), de 16.200 a $26.600 \mathrm{~kg} \mathrm{MS/ha,} \mathrm{respectivamente.}$

O híbrido CO 32 se destacou também pela produtividade de MS da planta, que aumentou de forma linear crescente $(\mathrm{P}<0,01)$ de acordo com a idade de corte (Tabela 5), assim como observado por Beleze et al. (2003). À medida que seu estádio de maturação avançou um dia, a produtividade de MS aumentou em torno de 120,26 kg/ha.

Os demais híbridos, agrupados pela semelhança do perfil de produção, apresentaram perfil quadrático $(\mathrm{P}<0,01)$ crescente com o tempo, semelhante ao encontrado por Cusicanqui \& Lauer (1999).

Com o avanço da maturação, não houve aumento na produção de colmo (Tabela 6), apesar de algumas oscilações observadas, provavelmente ocasionadas pelas alterações climáticas. As produções de colmo quando a planta

Tabela 4 - Produtividade média de matéria seca (kg/ha) da planta nas safras 2001/2002 e 2002/2003

\begin{tabular}{lccccccccc}
\hline Híbrido & \multicolumn{10}{c}{ Corte } & \multicolumn{1}{c}{ EP $^{1}$} \\
\cline { 2 - 7 } & 1 & 2 & 3 & 4 & 5 & 6 & 7 \\
\hline $2001 / 2002$ & $9.784 \mathrm{e}$ & $1.0038 \mathrm{e}$ & $12.234 \mathrm{Bd}$ & $14.458 \mathrm{Bc}$ & $15.165 \mathrm{Bc}$ & $17.673 \mathrm{Bb}$ & $17.488 \mathrm{Bb}$ & $19.360 \mathrm{a}$ & 610 \\
$2002 / 2003$ & $9.586 \mathrm{e}$ & - & $15.522 \mathrm{Ad}$ & $16.445 \mathrm{Ad}$ & $19.004 \mathrm{Ac}$ & $20.761 \mathrm{Ab}$ & $21.326 \mathrm{Ab}$ & $20.860 \mathrm{a}$ & 606 \\
\hline
\end{tabular}

${ }^{1} \mathrm{EPM}$ - erro-padrão da média.

Médias seguidas de letras diferentes, maiúsculas na coluna ou minúscula na linha, diferem $(\mathrm{P}<0,05)$ entre si pelo teste t de Student. 
Tabela 5 - Equações de regressão da produtividade de matéria seca da planta e do colmo da planta

\begin{tabular}{|c|c|c|}
\hline Híbrido & Safra $^{1}$ & Equação de regressão ${ }^{2}$ \\
\hline \multicolumn{3}{|c|}{ Produtividade de matéria seca da planta } \\
\hline \multirow[t]{2}{*}{ CO 32} & $2001 / 2002$ & PMS $=29,89+120,26 *$ DAS \\
\hline & $2002 / 2003$ & PMS $=3691+120,26 *$ DAS \\
\hline \multirow{2}{*}{$\begin{array}{l}\text { AG 5011, P 3041, DKB 333B, } \\
\text { AG } 1051 \text { e Z } 8550\end{array}$} & $2001 / 2002$ & $\mathrm{PMS}=-14612,11+405,09 * \mathrm{DAS}-1,0057 * \mathrm{DAS}^{2}$ \\
\hline & $2002 / 2003$ & PMS $=-10951+405,09 *$ DAS $-1,0057 * \mathrm{DAS}^{2}$ \\
\hline \multicolumn{3}{|c|}{ Produtividade de matéria seca do colmo da planta } \\
\hline \multirow[t]{2}{*}{ CO 32} & $2001 / 2002$ & PMSC $=16126,46-248,68 *$ DAS $+1,2239 *$ DAS $^{2}$ \\
\hline & $2002 / 2003$ & PMSC $=17088,35-248,68 *$ DAS $+1,2239 *$ DAS $^{2}$ \\
\hline \multirow{2}{*}{ AG 5011, P 3041, DKB 333B e Z 8550} & $2001 / 2002$ & PMSC $=3200,46+23,4486 *$ DAS \\
\hline & $2002 / 2003$ & PMSC $=4162,35+23,4486 *$ DAS \\
\hline \multirow[t]{2}{*}{ AG 1051} & $2001 / 2002$ & PMSC $=6509,36$ \\
\hline & $2002 / 2003$ & PMSC $=7471,25$ \\
\hline
\end{tabular}

${ }^{1}$ Safra 2001/2002: CO 32 - 67 a 122 DAS; AG 5011 - 67 a 122 DAS; P 3041 - 63 a 118 DAS; DKB 333B - 70 a 126 DAS; AG 1051 - 70 a 126 DAS; Z 8550 - 63 a 118 DAS; Safra 2002/2003: CO 32 - 64 a 119 DAS; AG 5011 - 59 a 115 DAS; P 3041 - 59 a 115 DAS; DKB 333B - 64 a 119 DAS; AG 1051 - 64 a 119 DAS; Z 8550 59 a 115 DAS.

2 PMS - produtividade de MS; DAS - dias após a semeadura; PMSC - produtividade de MS do colmo.

Tabela 6 - Produtividade média de colmo (kg MS/ha) dos híbridos de milho e das safras 2001/2002 e 2002/2003

\begin{tabular}{|c|c|c|c|c|c|c|c|c|c|}
\hline \multirow[t]{2}{*}{ Híbrido } & \multicolumn{8}{|c|}{ Corte } & \multirow[t]{2}{*}{$\mathrm{EPM}^{1}$} \\
\hline & 1 & 2 & 3 & 4 & 5 & 6 & 7 & 8 & \\
\hline CO 32 & $59.37 \mathrm{BCa}$ & - & $4.290 \mathrm{Cb}$ & $3.952 \mathrm{Cb}$ & $4.222 \mathrm{Cb}$ & $4.744 \mathrm{Bb}$ & $4.299 \mathrm{Cb}$ & $4.170 \mathrm{Db}$ & 424 \\
\hline AG 5011 & $5.600 \mathrm{Cb}$ & - & $50.69 \mathrm{BCb}$ & $5.541 \mathrm{ABb}$ & $5.224 \mathrm{Cb}$ & 7.012Aa & 6.003ABab & $5.769 \mathrm{Cb}$ & 434 \\
\hline P 3041 & $5.233 \mathrm{Cb}$ & - & $4.978 \mathrm{BCb}$ & $5.464 \mathrm{ABb}$ & $6.735 \mathrm{Ba}$ & $7.027 \mathrm{Aa}$ & $7.052 \mathrm{Aa}$ & $6.021 \mathrm{Bab}$ & 424 \\
\hline DKB 333B & 6.839ABab & - & $6.108 \mathrm{ABb}$ & $6.034 \mathrm{ABb}$ & $6.499 \mathrm{Bbc}$ & $7.574 \mathrm{Aac}$ & $7.873 \mathrm{Aa}$ & 7.202ABab & 438 \\
\hline AG 1051 & $7.711 \mathrm{Aa}$ & - & $6.336 \mathrm{Ac}$ & 6.362Abc & 7.939Aa & 7.299Аас & 7.478Аас & $7.294 \mathrm{Aac}$ & 429 \\
\hline Z 8550 & $5.238 \mathrm{Cb}$ & - & $4.938 \mathrm{CBb}$ & $5.155 \mathrm{Bb}$ & 5.702BCab & $6.588 \mathrm{Aa}$ & $5.193 \mathrm{BCb}$ & 6.000BCab & 424 \\
\hline \multicolumn{10}{|l|}{ Safra } \\
\hline $2001 / 2002$ & $6.212 \mathrm{a}$ & $4780 c$ & $5.006 \mathrm{c}$ & $4.852 \mathrm{BC}$ & $5.395 \mathrm{Bbc}$ & 5.982Bab & 5.892Bab & $5.757 a b$ & 247 \\
\hline $2002 / 2003$ & $5.974 \mathrm{~cd}$ & - & $5.568 \mathrm{~d}$ & 5.984Acd & $6.712 \mathrm{Ab}$ & 7.432Aa & $6.741 \mathrm{Ab}$ & $6.395 b c$ & 248 \\
\hline
\end{tabular}

${ }^{1} \mathrm{EPM}$ - erro-padrão da média.

Médias seguidas de letras diferentes, maiúscula na coluna ou minúscula na linha, diferem entre si $(P<0,05)$ pelo teste t de Student.

apresentou 32 a 35\% de MS variaram de 5.395 a $7.432 \mathrm{~kg}$ MS/ha nas duas safras avaliadas. Segundo Darby \& Lauer (2002), a ausência de variação na produtividade de colmo no período avaliado pode ser explicada pelo fato de que a máxima produção da fração fibrosa da planta é atingida quando se inicia a fase reprodutiva, que, no caso deste estudo, ocorreu no momento da primeira avaliação (1으 corte), em torno de 60 a 70 dias após a semeadura.

Produções de colmo bem inferiores às deste estudo foram encontradas por Beleze et al. (2003), de 2.400 a $3.760 \mathrm{~kg}$ MS/ha em plantas colhidas 125 a 164 dias póssemeadura. Produções de 7.200 kg MS/ha, mais próximas das observadas neste estudo foram obtidas por Ferreira et al. (2006), no entanto, essa produtividade foi referente à fração colmo + folha de plantas colhidas no ponto de maturidade fisiológica.

Silva et al. (1999) observaram produções de 4.750 a $11.600 \mathrm{~kg}$ MS/ha da fração fibrosa da planta constituída de colmo e folhas, cujo corte foi realizado com os grãos no ponto farináceo duro. Portanto, é evidente que características intrínsecas dos híbridos, além dos fatores edafoclimáticos, são responsáveis pela grande variabilidade de resultados.

Os híbridos P 3041, DKB 333B e AG 1051 apresentaram as maiores $(\mathrm{P}<0,05)$ produções de colmo, e o híbrido CO 32 foi o que em média resultou nas menores $(\mathrm{P}<0,05)$ produções de colmo no período de avaliação. Silva et al. (1997) avaliaram cultivares de milho para silagem e obtiveram produções de colmo para o híbrido AG 1051 de $3.290 \mathrm{~kg}$ MS/ha em plantas colhidas com 31,5\% de MS. Neste estudo, a produtividade deste híbrido em plantas com o mesmo teor de MS foi de $7.940 \mathrm{~kg}$ MS/ha. Beleze et al. (2003) também observaram valores bem inferiores de produções de colmo para o híbrido P 3041: em plantas com 26,1 a 40,5\% de MS obtiveram produções de colmo entre 3.140 e $3.620 \mathrm{~kg} \mathrm{MS} / \mathrm{ha}$. Neste estudo, as produções deste híbrido foram de 5.460 a $7.050 \mathrm{~kg}$ MS/ha em plantas com 23,9 a 41,2\% de MS, o que pode ser explicado pelo fato de as plantas neste estudo terem sido cortadas a $8 \mathrm{~cm}$ do solo, 
enquanto, no experimento realizado por Beleze et al. (2003), o corte foi realizado a $45 \mathrm{~cm}$ do solo, o que reduziu a quantidade de colmo colhido.

Os híbridos CO 32 e AG 1051 apresentaram perfis distintos entre si e dos demais materiais, por isso, equações de regressão específicas foram criadas para cada um deles (Tabela 5). Para o híbrido CO 32, a produtividade de colmo apresentou efeito quadrático $(\mathrm{P}<0,01)$. Beleze et al. (2003) encontraram efeitos semelhantes em híbridos colhidos entre 125 e 164 DAS. Segundo esses autores, este efeito pode ocorrer em virtude de uma variação na concentração de nutrientes com o avanço da maturação da planta.

O híbrido AG 1051 não apresentou efeito de idade sobre a produtividade de colmo, que se manteve constante nas safras 2001/2002 e 2002/2003, com valores de 6.509 e $7.471 \mathrm{~kg}$ MS/ha (Tabela 5), respectivamente.

Os demais híbridos apresentaram efeito linear crescente $(\mathrm{P}<0,01)$ para produtividade de MS do colmo ao longo do tempo. O avanço da maturação da planta resultou em aumentos de produtividade de MS de 23,45 kg MS/ha por dia, atingindo valores máximos de 6.100 e 7.100 kg MS/ha nas safras 2001/2002 e 2002/2003, respectivamente.

Apesar da maior porcentagem de MS observada no colmo do híbrido CO 32, isso não resultou em maior produtividade desta fração na planta. Uma possível explicação para esses efeitos seria a altura inferior destas plantas ou o menor diâmetro dos colmos, que, mesmo com maiores teores de MS, não resultaram em maiores produções desta fração.

À medida que a planta avançou em desenvolvimento, a produtividade de grãos aumentou $(\mathrm{P}<0,05)$ atingindo produções no ponto de ensilagem (5으 e 6으 corte) de 4.674 a $6.040 \mathrm{~kg}$ MS/ha na safra 2001/2002, e 6.510 a $7.745 \mathrm{~kg}$ MS/ha na safra 2002/2003 (Tabela 7), provavelmente em virtude do acúmulo de MS, decorrente do enchimento dos grãos (Fancelli \& Dourado Neto, 2000).

Russell et al. (1992) encontraram produções de grãos semelhantes em híbridos de milho de ciclo normal e precoce colhidos quando a planta apresentava teores de MS um pouco acima do percentual preconizado como ideal, variando de 37,7 e 45,7\% de MS, respectivamente, com produção de 6.700 kg MS para os híbridos normais e de 7.700 kg MS para os cultivares precoces, valores próximos aos encontrados por Beleze et al. (2003), de 6.850 a 8.460 kg MS/ha entre 125 e 164 dias pós-semeadura.

Entretanto, Jaremtchuk et al. (2005) encontraram produções bem superiores, entre 9.400 e $12.700 \mathrm{~kg}$ MS/ha, em híbridos colhidos quando o grão se encontrava com $1 / 3$ da linha do leite. Neste estudo, essas produções foram atingidas somente nos estádios finais de avaliação, quando a planta apresentava em torno de 45,9\% de MS.

Farnham (2001) e Farinelli et al. (2003) obtiveram produções nesta faixa somente quando os grãos atingiram a maturidade fisiológica, portanto, as produções encontradas neste trabalho parecem estar dentro do encontrado na literatura para o período de avaliação. Farinelli et al. (2003) encontraram produções de grãos semelhantes em plantio de safra para os híbridos CO 32, DKB 333B e Z 8550 no ponto de maturidade fisiológica do grão, de 8.813; 11.177 e $9.723 \mathrm{~kg} \mathrm{MS} / \mathrm{ha}$, respectivamente.

Para os híbridos CO 32 e AG 5011, gerou-se uma única equação de regressão para cada safra, uma vez que esses híbridos apresentaram perfil semelhante (Tabela 8). Da mesma forma, os híbridos P 3041, DKB 333B e AG 1051 também foram agrupados, enquanto o híbrido Z 8550 foi avaliado individualmente.

De acordo com as equações de regressão obtidas para os híbridos CO 32 e AG 5011, houve efeito linear crescente $(\mathrm{P}<0,01)$ dos dias após a semeadura sobre a produtividade de grãos; no período de avaliação, a produtividade aumentou aproximadamente $145 \mathrm{~kg}$ MS/ha por dia. Efeito linear crescente $(\mathrm{P}<0,01)$ também foi observado para os híbridos $\mathrm{P}$ 3041, DKB 333B e AG 1051. Para estes materiais, avanços da idade da planta ocasionaram aumentos de produtividade de cerca de $182 \mathrm{~kg}$ MS/ha por dia. Para o híbrido Z 8550, verificou-se efeito quadrático $(\mathrm{P}<0,01)$ da idade da planta sobre a produtividade de grãos.

Efeito linear semelhante foi observado por Beleze et al. (2003) em híbridos de milho avaliados entre 125 e 164 DAS, no entanto, esses autores observaram aumentos diários de 51 a 65 kg MS/ha na produtividade de grãos.

No híbrido Z 8550, houve efeito quadrático crescente $(\mathrm{P}<0,01)$ dos dias após a semeadura sobre as produções

Tabela 7 - Produtividade média de grãos (kg MS/ha) nas safras 2001/2002 e 2002/2003

\begin{tabular}{|c|c|c|c|c|c|c|c|c|c|}
\hline \multirow[t]{2}{*}{ Híbrido } & \multicolumn{8}{|c|}{ Corte } & \multirow[t]{2}{*}{$\mathrm{EPM}^{1}$} \\
\hline & 1 & 2 & 3 & 4 & 5 & 6 & 7 & 8 & \\
\hline $2001 / 2002$ & $0 \mathrm{f}$ & $419 \mathrm{f}$ & $1.436 \mathrm{Be}$ & $2.977 \mathrm{Bd}$ & $4.674 \mathrm{Bc}$ & $6.040 \mathrm{Bb}$ & $6.291 \mathrm{Bb}$ & $9.150 \mathrm{a}$ & 263 \\
\hline $2002 / 2003$ & of & - & $3.337 \mathrm{Ae}$ & $5.220 \mathrm{Ad}$ & $6.510 \mathrm{Ac}$ & $7.745 \mathrm{Ab}$ & 8.802Aab & $9.254 \mathrm{a}$ & 263 \\
\hline
\end{tabular}

${ }^{1}$ EPM - erro padrão da média.

Médias seguidas de letras diferentes, maiúscula na coluna ou minúscula na linha, diferem $(\mathrm{P}<0,05)$ entre si pelo teste t de Student. 
Tabela 8 - Equações de regressão da produtividade de grãos

\begin{tabular}{lcc}
\hline Híbrido & Safra $^{1}$ & Equação de regressão $^{2}$ \\
\hline CO 32 e AG 5011 & $2001 / 2002$ & PG $=-10581,58+144,48 *$ DAS \\
& $2002 / 2003$ & PG $=-8167,61+144,48 *$ DAS \\
P 3041, DKB 333B e AG 1051 & $2001 / 2002$ & PG $=-13652,54+181,83 *$ DAS \\
& $2002 / 2003$ & PG $=-11238,57+181,83 *$ DAS \\
Z 8550 & $2001 / 2002$ & PG $=-10581,58+116,87 *$ DAS $+0,3884 *$ DAS \\
& $2002 / 2003$ & PG $=-8167,61+116,87 *$ DAS $+0,3884 *$ DAS \\
\hline
\end{tabular}

1 Safra 2001/2002: CO 32 - 67 a 122 DAS; AG 5011 - 67 a 122 DAS; P 3041 - 63 a 118 DAS; DKB 333 B - 70 a 126 DAS; AG 1051 - 70 a 126 DAS; Z 8550 - 63 a 118 DAS; Safra 2002/2003: CO 32 - 64 a 119 DAS; AG 5011 - 59 a 115 DAS; P 3041 - 59 a 115 DAS; DKB $333 B$ - 64 a 119 DAS; AG 1051 - 64 a 119 DAS; Z 8550 59 a 115 DAS.

2 PG - Produtividade de grãos; DAS - dias após a semeadura

máximas de 10.100 e $12.500 \mathrm{~kg}$ MS/ha nas safras 2001/2002 e 2002/2003, respectivamente.

Os baixos coeficientes de correlação $(\mathrm{P}<0,05)$ encontrados, tanto entre o teor de MS da planta e as produções de MS da planta, produções de colmo e de grãos, como entre o teor de MS do colmo e a produtividade de MS da planta e do colmo (Tabela 9), justificam o fato de o híbrido CO 32 ter apresentado os maiores teores de MS da planta e do colmo (Tabela 2) sem apresentar, no entanto, maiores produções de MS da planta e MS do colmo (Tabela 6).

Os coeficientes entre produtividade de colmo e de grão $\left(r^{2}=0,43\right)$ neste estudo foram baixos $(P<0,01)$, como observado por Wolf et al. (1993), que verificaram correlações significativas $(P<0,05)$, porém baixas $\left(r^{2}=0,46\right)$, entre estas variáveis. Tolera et al. (1999) encontraram correlações significativas $(\mathrm{P}<0,01)$ e altas $\left(\mathrm{r}^{2}=0,77\right)$ entre a produtividade de MS da planta e a produtividade de MS da fração fibrosa de plantas colhidas no ponto de maturidade fisiológica. Os coeficientes de correlação entre a produtividade de grãos e a produtividade de matéria seca da planta foram significativos $(\mathrm{P}<0,01)$ e positivos $\left(\mathrm{r}^{2}=0,72\right)$, evidenciando que ganhos em produtividade de MS são acompanhados de ganhos em produtividade de grãos. Wolf et al. (1993) também encontraram correlações positivas significativas $\left(r^{2}=0,65\right)$ entre produtividade de grãos e produtividade de MS da planta, assim como Tolera et al. (1999), que verificaram coeficientes de correlação de $0,81(\mathrm{P}<0,01)$.

Tabela 9 - Coeficientes de correlação das variáveis estudadas para os híbridos de milho

\begin{tabular}{lccccc}
\hline Variável $^{1}$ & MSP & MSC & PMS & PMSC & PG \\
\hline MSP & - & $0,4479^{* *}$ & $0,2747^{* *}$ & $0,1258^{*}$ & $0,3968^{* *}$ \\
MSC & & - & $-0,2571^{* *}$ & $-0,1799^{* *}$ & $-0,0813$ \\
PMS & & & - & $0,8316^{* *}$ & $0,7185^{* *}$ \\
PMSC & & & & - & $0,4296^{* *}$ \\
\hline
\end{tabular}

$* \mathrm{P}<0,05 ; * * \mathrm{P}<0,01$.

MSP - MS da planta; MSC - MS do colmo; PMS - produtividade de MS da planta; PMSC -produtividade de MS do colmo; PG - produtividade de grãos.
Portanto, os resultados observados indicam que alguns híbridos de milho podem apresentar perfis diferenciados, atingindo o momento ideal de corte para ensilagem em diferentes idades, o que exige avaliação mais criteriosa de cada material para obtenção de um produto de qualidade, que resulte em resposta animal satisfatória. Além disso, plantas colhidas com maiores teores de MS não apresentaram maiores produções de MS, produções de colmo ou de grão.

Desta forma, outros critérios devem ser adotados na decisão sobre o momento ideal de corte da planta, considerando que teores muito elevados de MS representam problemas, tanto na picagem da forragem quanto em sua compactação, e que teores baixos resultam em fermentações inadequadas, decorrentes do desenvolvimento de organismos indesejáveis, como o Clostridium (McDonald et al., 1991).

\section{Conclusões}

O avanço da maturação ocasiona aumento dos teores de MS da planta e do colmo, da produtividade de MS da planta e da produtividade de grãos. No entanto, o aumento no teor de MS da planta não resulta em maiores ganhos em produtividade de MS da planta e do colmo nem em maior produtividade de grãos. A ocorrência de características agronômicas distintas entre os híbridos requer a avaliação individual do momento ideal de corte da planta para ensilagem, visando atingir o potencial máximo de cada híbrido. Portanto, somente com muito critério plantas colhidas em estádios fisiológicos diferentes podem ser comparadas quanto à participação das frações, uma vez que a época de corte pode alterar significativamente a composição morfológica da planta.

\section{Agradecimentos}

À Apta Regional, pelo apoio para a realização deste trabalho. À CAPES, pela concessão de bolsa de estudos. À 
equipe de Qualidade e Conservação de Forragens da USP/ ESALQ, pelo apoio na condução dos trabalhos de campo.

\section{Literatura Citada}

BAL, M.A.; COORS, J.G.; SHAVER, R.D. Impact of maturity of corn for use as silage in the diets of dairy cows on intake, digestion and milk production. Journal of Dairy Science, v.80, n.10, p.2497-2503, 1997

BALLARD, C.S.; THOMAS, E.D.; TSANG, D.S. et al. Effect of corn silage hybrid on dry matter yield, nutrient composition, in vitro digestion, intake by dairy heifers, and milk production by dairy cows. Journal of Dairy Science, v.84, p.442-452, 2001.

BELEZE, J.R.F.; ZEOULA, L.M.; CECATO, U. et al. Avaliação de cinco híbridos de milho (Zea mays L.) em diferentes estádios de maturação. 1. Produtividade, características morfológicas e correlações. Revista Brasileira de Zootecnia, v.32, n.3, p.529-537, 2003.

CAMPOS, F.P.; NUSSIO, L.G.; NUSSIO, C.M.B. Métodos de análises de alimentos. Piracicaba: Fundação de Estudos Agrários Luiz de Queiroz, 2002. 102p.

CRUZ, J.C.; PEREIRA FILHO, I.A. Cultivares de milho para silagem. In: CRUZ, J.C.; PEREIRA FILHO, I.A.; RODRIGUES, J.A.S. (Eds.) Produção e utilização de silagem de milho e sorgo. Sete Lagoas: Embrapa Milho e Sorgo, 2001. p.11-37.

CUSICANQUI, J.A.; LAUER, J.G. Plant density and hybrid influence on corn forage yield and quality. Agronomy Journal, v.91, p.911-915, 1999.

DARBY, H.M.; LAUER, J.G. Harvest date and hybrid influence on corn forage yield, quality, and preservation. Agronomy Journal, v.94, p.559-566, 2002.

DUARTE, A.P.; KIEHL, J.C.; CAMARGO, M.A.F. et al. Acúmulo de matéria seca e nutrientes em cultivares de milho originárias de clima tropical e introduzidas de clima temperado. Revista Brasileira de Milho e Sorgo, v.2, n.3, p.1-20, 2003.

FANCELli, Al.; DOURADO NETO, D. Produção de milho. Guaíba: Agropecuária, 2000. 360p.

FARNHAM, D.E. Row spacing, plant density, and hybrid effects on corn grain yield and moisture. Agronomy Journal, v.93, p.1049-1053, 2001.

FARINELLI, R.; PENARIOL, F.G.; BORDIN, F. et al. Desempenho agronômico de cultivares de milho nos períodos de safra e safrinha. Bragantia, v.62, n.2, p.235-241, 2003.

FERNANDES, L.O.; PAES, J.M.V.; REIS, R.A. et al. Avaliação de cultivares de milho e sorgo para a produção de silagem: desempenho animal, produção e composição química da matéria seca. In: REUNIÃO ANUAL DA SOCIEDADE BRASILEIRA DE ZOOTECNIA, 41., 2004, Campo Grande. Anais... Campo Grande: Sociedade Brasileira de Zootecnia, 2004. (CD-ROM).

FERREIRA, J.J. Características qualitativas e produtivas da planta de milho e sorgo para silagem. In: CRUZ, J.C.; PEREIRA FILHO, I.A.; RODRIGUES, J.A.S. et al. (Eds.) Produção e utilização de silagem de milho e sorgo. Sete Lagoas: Embrapa Milho e Sorgo, 2001. p.383-404.

FERREIRA, J.J.; RUAS, J.R.M.; SILVA, E.A. et al. Produção de grãos e fração fibrosa por diferentes cultivares de milho nos estágios de silagem e maturação completa. In: REUNIÃO ANUAL DA SOCIEDADE BRASILEIRA DE ZOOTECNIA, 43., 2006, João
Pessoa. Anais... João Pessoa: Sociedade Brasileira de Zootecnia, 2006. (CD-ROM).

FILYA, I. Nutritive value and aerobic stability of whole crop maize silage harvested at four stages of maturity. Animal Feed Science and Technology, v.116, p.141-150, 2004.

JAREMTCHUK, A.R.; JAREMTCHUK, C.C.; BAGLIOLI, B. et al. Características agronômicas e bromatológicas de vinte genótipos de milho (Zea mays L.) para silagem na região leste paranaense. Acta Scientiarum of Animal Science, v.27, n.2, p.181-188, 2005.

McDOnALD, P.; HENDERSON, A.R.; HERON, S.J.E. The biochemistry of silage. 2.ed. Merlow: Chalcombe Publications, 1991. 340p.

NEUMANN, M.; OST, P.R.; LUSTOSA, S.B.C. et al. Comportamento produtivo de híbridos de milho (Zea mays L.) e sorgo (Sorghum bicolor) para produção de silagem. In: REUNIÃO ANUAL DA SOCIEDADE BRASILEIRA DE ZOOTECNIA, 43., 2006, João Pessoa. Anais... João Pessoa: Sociedade Brasileira de Zootecnia, 2006. (CD-ROM).

NUSSIO, L.G.; MANZANO, R.P. Silagem de milho. In: SIMPÓSIO SOBRE NUTRIÇÃO DE BOVINOS: ALIMENTAÇÃO SUPLEMENTAR, 7., 1999, Piracicaba. Anais... Piracicaba: Fundação de Estudos Agrários Luiz de Queiroz, 1999. p.27-46

ROSA, J.R.P.; RESTLE, J.; SILVA, J.H.S. et al. Avaliação da silagem de diferentes híbridos de milho (Zea mays L.) por meio do desempenho de bezerros confinados em fase de crescimento. Revista Brasileira de Zootecnia, v.33, n.4, p.1016-1028, 2004.

ROTH, M.T.P.; REIS, R.A.; BERNARDES, T.F. et al. Produção e composição química de híbridos de milho (Zea mays L.) para silagem. In: REUNIÃO ANUAL DA SOCIEDADE BRASILEIRA DE ZOOTECNIA, 41., 2004, Campo Grande. Anais... Campo Grande: Sociedade Brasileira de Zootecnia, 2004. (CD-ROM).

RUSSELL, J.R. Influence of harvest date on the nutritive value and ensiling characteristics of maize stover. Animal Feed Science and Technology, v.14, p.11-27, 1986.

RUSSELL, J.R.; IRLBECK, N.A.; HALLAUER, A.R. et al. Nutritive value and ensiling characteristics of maize herbage as influenced by agronomic factors. Animal Feed Science and Technology, v.38, p.11-24, 1992.

STATISTICAL ANALYSIS SYSTEM - SAS. SAS OnlineDoc. Version 9.1.3. Cary: SAS Institute, 2004. (CD-ROM).

SILVA, J.M.; KICHEL, A.N.; FEIJÓ, G.L.D. et al. Avaliação de cultivares de milho e sorgo para a produção de silagem. In: REUNIÃO ANUAL DA SOCIEDADE BRASILEIRA DE ZOOTECNIA, 34., 1997, Juiz de Fora. Anais... Juiz de Fora: Sociedade Brasileira de Zootecnia, 1997. v.1, p.187-189.

SILVA, L.F.P.; MACHADO, P.F.; FRANCISCO JR., J.C. et al. Características agronômicas e digstibilidade in situ da fração volumosa de híbridos de milho para silagem. Scientia Agrícola, v.56, n.1, p.171-184, 1999

TOLERA, A.; BERG, T.; SUNDSTOL, F. The effect of variety on maize grain and crop residue yield and nutritive value of the stover. Animal Feed Science and Technology, v.79, p.165$177,1999$.

WILKINSON, J.M.; HILL, J. Effect on yield and dry matter distribution of the stay green characteristic in cultivars of forage maize grown in England. Grass and Forage Science, v.58, p.258-264, 2003.

WOLF, D.P.; COORS, J.G.; ALBRECHT, K.A. et al. Agronomic evaluations of maize genotypes selected for extreme fiber concentrations. Crop Science, v.33, p.1359-1365, 1993. 